\title{
Solution-Processed OLEDs Based on Thermally Activated Delayed Fluorescence Copper(I) Complexes with Intraligand Charge-Transfer Excited State
}

\author{
Teng Teng ${ }^{1,2,+}$, Jinfan Xiong ${ }^{1,+}$, Gang Cheng ${ }^{3}$, Changjiang Zhou ${ }^{1,2}$, Xialei Lv ${ }^{1,2}$ and Kai Li ${ }^{1, * \mathbb{C}}$ \\ 1 College of Materials Science and Engineering, Shenzhen University, Shenzhen 518055, China; \\ tteng-happy@outlook.com (T.T.); xiongjinfan123@gmail.com (J.X.); changjiang7pao@sina.com (C.Z.); \\ lvx10907@163.com (X.L.) \\ 2 College of Physics and Optoelectronic Engineering, Shenzhen University, Shenzhen 518060, China \\ 3 State Key Laboratory of Synthetic Chemistry, HKU-CAS Joint Laboratory on New Materials, Department of \\ Chemistry, The University of Hong Kong, Pokfulam Road, Hong Kong, China; ggcheng@hku.hk \\ * Correspondence: kaili@szu.edu.cn \\ + These authors contributed equally to this work.
}

check for updates

Citation: Teng, T.; Xiong, J.; Cheng, G.; Zhou, C.; Lv, X.; Li, K.

Solution-Processed OLEDs Based on Thermally Activated Delayed Fluorescence Copper(I) Complexes with Intraligand Charge-Transfer Excited State. Molecules 2021, 26, 1125. https://doi.org/10.3390/ molecules26041125

Academic Editor: Carlo Santoro

Received: 27 January 2021

Accepted: 12 February 2021

Published: 20 February 2021

Publisher's Note: MDPI stays neutral with regard to jurisdictional claims in published maps and institutional affiliations.

Copyright: (c) 2021 by the authors. Licensee MDPI, Basel, Switzerland. This article is an open access article distributed under the terms and conditions of the Creative Commons Attribution (CC BY) license (https:/ / creativecommons.org/licenses/by/ $4.0 /)$.

\begin{abstract}
A new series of tetrahedral heteroleptic copper(I) complexes exhibiting efficient thermallyactivated delayed fluorescence (TADF) in green to orange electromagnetic spectral regions has been developed by using D-A type $\mathrm{N}^{\wedge} \mathrm{N}$ ligand and $\mathrm{P}^{\wedge} \mathrm{P}$ ligands. Their structures, electrochemical, photophysical, and electroluminescence properties have been characterized. The complexes exhibit high photoluminescence quantum yields (PLQYs) of up to 0.71 at room temperature in doped film and the lifetimes are in a wide range of 4.3-24.1 $\mu \mathrm{s}$. Density functional theory (DFT) calculations on the complexes reveal the lowest-lying intraligand charge-transfer excited states that are localized on the $\mathrm{N}^{\wedge} \mathrm{N}$ ligands. Solution-processed organic light emitting diodes (OLEDs) based on one of the new emitters show a maximum external quantum efficiency (EQE) of $7.96 \%$.
\end{abstract}

Keywords: $\mathrm{Cu}(\mathrm{I})$ complexes; TADF; intraligand charge-transfer; OLED; solution process

\section{Introduction}

Emissive triplet states of transition metal complexes underpin a wide range of advanced optoelectronic applications, such as organic light emitting diodes (OLEDs) and biological studies [1-7]. The relatively long excited-state lifetimes in the microsecond regime owing to the spin-forbidden nature of triplet excited states are also desired for photochemical reactions and triplet-triplet annihilation based upconversion (TTA-UC) involving bimolecular electron and/or energy transfer processes [8-10]. These fields have been dominated by phosphorescent transition metal complexes based on the platinum group metals (PGMs), such as iridium, platinum, and ruthenium because of their significant spin-orbit coupling (SOC) constants [1-10]. The practical use of $\operatorname{Ir}(\mathrm{III})$ emitters in current commercial OLEDs possibly suggests the advantage of metal complexes in the device operational stability. However, the natural abundances of these metals are extremely low, thereby limiting their practical applications. Therefore, research endeavors to the exploration of alternative luminescent molecular materials with reliable resources and low cost is demanding [11,12]. In this context, luminescent coinage metal complexes have been studied for decades but their applications to OLEDs are greatly restricted. The relatively weak SOC constants (for $\mathrm{Ag}$ and $\mathrm{Cu}$ ) or the high oxidation potentials (for $\mathrm{Au}(\mathrm{III})$ ) of the coinage metal ions renders their triplet excited states to have long emission lifetimes that are detrimental to electroluminescence devices [13,14].

The thermally activated delayed fluorescence (TADF) of pure organic compounds has clearly shown the capability to harvest triplet excitons in OLEDs in the absence of heavy atoms [15]. Instead of radiative decay to ground state, the triplet excited state of a 
TADF emitter is thermally pumped to the singlet excited state through reverse intersystem crossing (RISC) which then radiates rapidly. In parallel with the advances of pure organic luminescent materials, TADF cuprous complexes have also witnessed a great stride which now show promising device performances that become comparable to phosphorescent noble metal complexes in terms of device efficiency [16-27]. The TADF mechanism allows $\mathrm{Cu}(\mathrm{I})$ complexes to bypass the slow radiative decay of triplet excited states of $\mathrm{Cu}(\mathrm{I})$ emitters. In addition, the SOC of light metals, although weak, may still has non-negligible positive effect in boosting the RISC process. In comparison with the pure organic TADF emitters, which are designed by engineering, the donor, and acceptor through a highly twisted through-bond connection or a through-space charge-transfer interaction (Figure 1a-c), molecular geometries of $\mathrm{Cu}(\mathrm{I})$ complexes can be facilely controlled by the design or selection of ligand(s). Representative TADF Cu(I) complexes with tetrahedral, trigonal, and linear coordination geometries are shown in Figure 1 (Figure $1 \mathrm{~d}-\mathrm{f}$ ). Most of the TADF $\mathrm{Cu}(\mathrm{I})$ complexes adopt donor-metal-acceptor configuration and, thus, have ligand-to-ligand charge transfer (LLCT) excited states. In the literature, it has been shown that the TADF can also be achieved from intraligand charge-transfer excited state in $\mathrm{Pd}(\mathrm{II}), \mathrm{W}(\mathrm{VI})$, and $\mathrm{Au}$ (III) complexes supported by tetradentate ligands [28-30]. Likewise, this concept has recently been demonstrated on $\mathrm{Cu}(\mathrm{I})$ and $\mathrm{Ag}(\mathrm{I})$ complexes using simple TADF-inactive donor-acceptor type ligands (Figure 1f) $[19,31,32]$. The coordination with metal ion was found to affect the relative energy levels of lowest lying singlet and triplet excited states of the ligand, thus switching on the ligand-based TADF.

a)

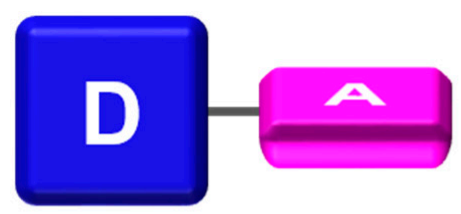

d)

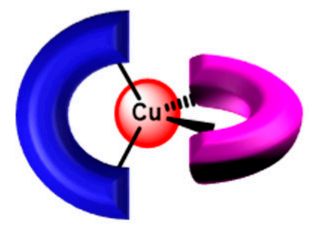

b)

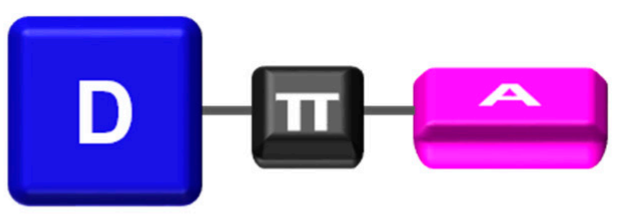

c)

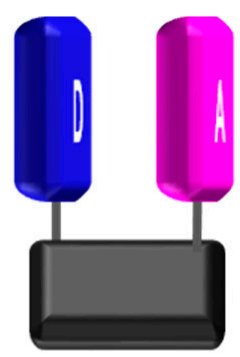

e)

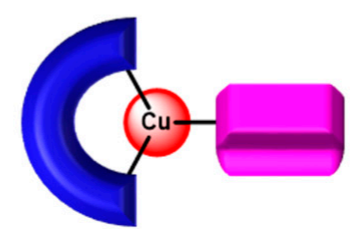

f)

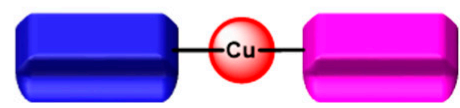

Figure 1. Molecule designs of organic and $\mathrm{Cu}(\mathrm{I})$ thermally-activated delayed fluorescence (TADF) emitters: (a) highly twisted D-A structure with through-bond charge transfer (TBCT) excited state; (b) separated D and A segments by a $\pi$ spacer; (c) intramolecular D-A pair with through-space charge transfer (TSCT) excited state; (d) tetrahedral, (e) trigonal, and (f) linear coordination geometries for $\mathrm{Cu}(\mathrm{I})$ complexes with predominant ligand-to-ligand charge transfer (LLCT) excited state.

Herein, four new $\mathrm{Cu}(\mathrm{I})$ complexes (Scheme 1) exhibiting intraligand TADF have been developed. Pyridine substituted 1-phenyl-1H-phenanthro[9,10-d]imidazole (PyPI) was modified with strong electron-donors of dimethyl-9,10-dihydroacridine (DMAC) or 10Hphenoxazine (PXZ) to construct charge-transfer type ligand. The bis[2-(diphenylphosphino) phenyl]-ether (POP) and 4,5-bis(diphenylphosphino)-9,9-dimethylxan-thene (Xantphos) ligands were used as the auxiliary ligands. These complexes exhibit efficient TADF with photoluminescence quantum yields (PLQYs) of up to 0.71 in doped film. Dependent on the donor, the delayed fluorescence lifetimes vary appreciably from $4 \mu \mathrm{s}$ to $21 \mu \mathrm{s}$. The involvement of triplet locally excited $\left({ }^{3} \mathrm{LE}\right)$ state in the RISC process likely exerts a positive effect on the RISC rate. Solution-processed OLEDs based on this type of emitter have been fabricated and achieved maximum external quantum efficiency (EQE) of up to $7.96 \%$. 


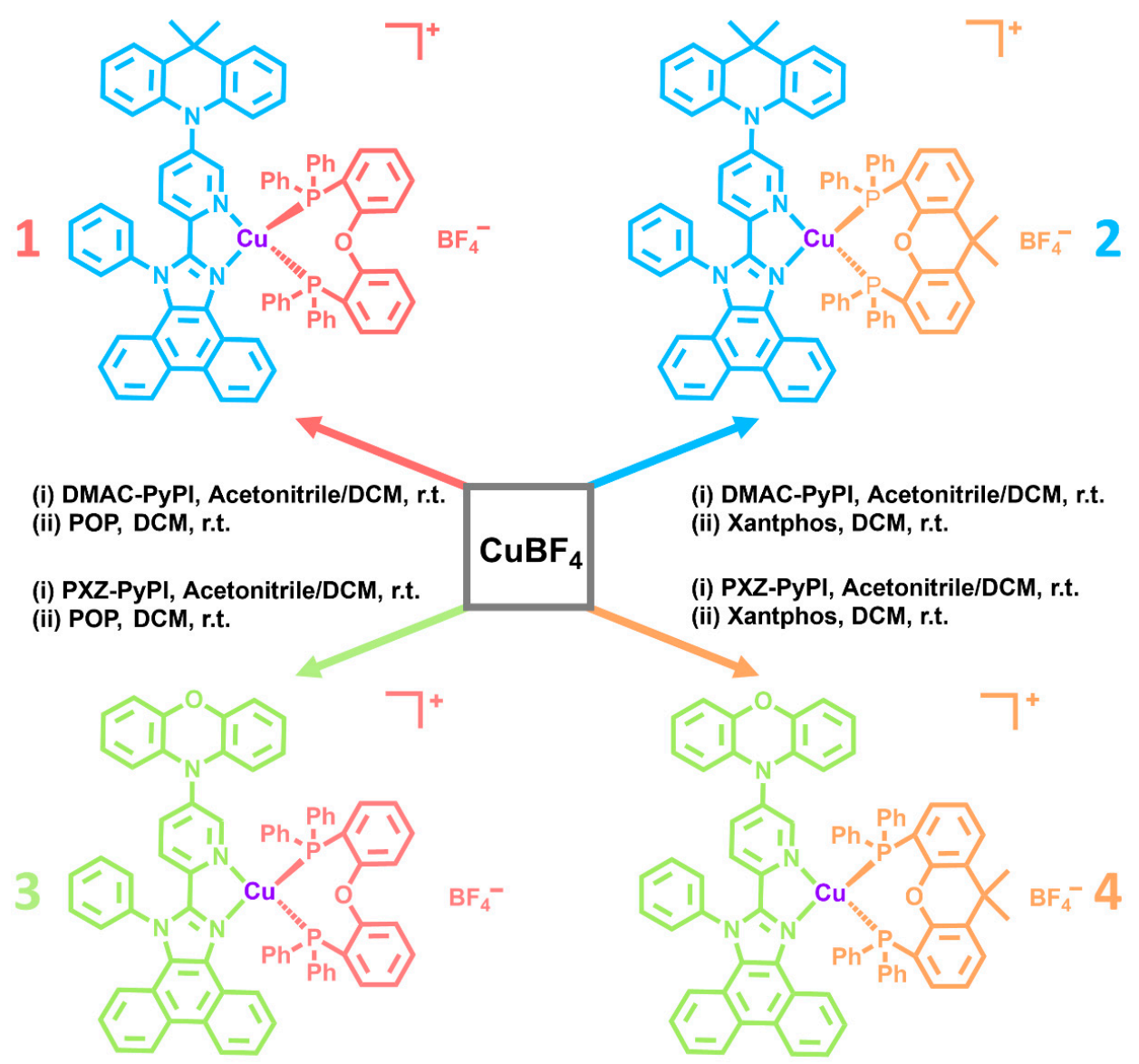

Scheme 1. Synthesis and chemical structures of the $\mathrm{Cu}(\mathrm{I})$ complexes 1-4 in this work.

\section{Results and Discussion}

\subsection{Synthesis and Structures}

The syntheses of the diimine ligands, 2-(5-(9,9-dimethylacridin-10(9H)-yl)pyridin2-yl)-1-phenyl-1H-phenanthro[9,10-d]imidazole (DMAC-PyPI) and 10-(6-(1-phenyl-1Hphenanthro[9,10-d]imidazol-2-yl)pyridin-3-yl)-10H-phenoxazine (PXZ-PyPI), have been described elsewhere [31]. As depicted in Scheme 1, all four cuprous complexes were prepared using a typical method and obtained as crystals in high yields of $77 \%-84 \%$. All complexes have been characterized by ${ }^{1} \mathrm{H}$ and ${ }^{31} \mathrm{P}\left\{{ }^{1} \mathrm{H}\right\}$ NMR spectra and elemental analysis. The thermal stability of all the complexes was examined by thermogravimetric analysis (TGA) under argon atmosphere. Their decomposition temperatures $\left(\mathrm{T}_{\mathrm{d}}\right)$ at a weight loss of $5 \%$ were determined to be from $345^{\circ} \mathrm{C}$ to $381{ }^{\circ} \mathrm{C}$ (Figure S1, Supplementary Materials).

Molecular structures of 1-4 have been determined through single-crystal X-ray diffraction studies and the crystal data are provided in Table S1 (Supplementary Materials). The selected bond lengths of $\mathrm{Cu}-\mathrm{N}$ and $\mathrm{Cu}-\mathrm{P}$ bonds and bond angles around the metal center are compiled in Table S2. As depicted in Figure 2, the $\mathrm{Cu}(\mathrm{I})$ ions in all crystal structures bind to a $\mathrm{N}^{\wedge} \mathrm{N}$ ligand and a $\mathrm{P}^{\wedge} \mathrm{P}$ ligand in a distorted tetrahedral coordination geometry. The $\mathrm{Cu}-\mathrm{N}$ and Cu-P bond lengths of 2.056(3)-2.139(3) $\AA$ and 2.218(2)-2.2941(15) $\AA$, respectively, are in the range for cationic $\left[\mathrm{Cu}\left(\mathrm{N}^{\wedge} \mathrm{N}\right)\left(\mathrm{P}^{\wedge} \mathrm{P}\right)\right]^{+}$complexes in the literature [33]. Likewise, the $\mathrm{N}-\mathrm{Cu}-\mathrm{N}$ and P-Cu-P bond angles in the range of 78.10(16)-79.98(11) and 115.41(4)-118.20(8), respectively, are among the typically reported values. The dihedral angles defined by the $\mathrm{N}^{\wedge} \mathrm{Cu}^{\wedge} \mathrm{N}$ and $\mathrm{P}^{\wedge} \mathrm{Cu} \mathrm{u}^{\wedge}$ planes are 85.3-89. $8^{\circ}$, revealing nearly orthogonal orientation of the chromophore $\mathrm{N}^{\wedge} \mathrm{N}$ and auxiliary $\mathrm{P}^{\wedge} \mathrm{P}$ ligands (Table S2, Supplementary Materials). The PXZ moieties in $\mathbf{3}$ and $\mathbf{4}$ are planar and strongly twisted from the $\mathrm{N}-\mathrm{Cu}-\mathrm{N}$ coordination plane by ca. $68^{\circ}$ and $69^{\circ}$, respectively. In contrast, the DMAC in 1 and 2 slightly deviate from an ideal plane. 


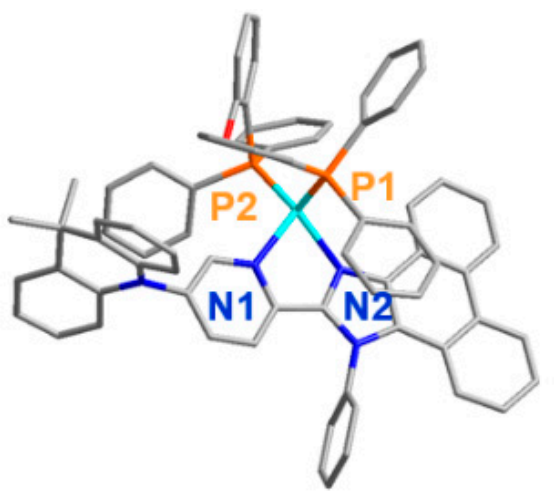

1

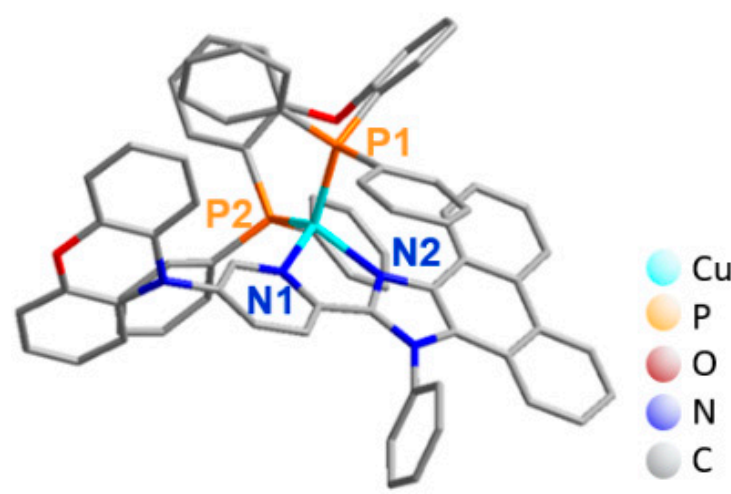

3

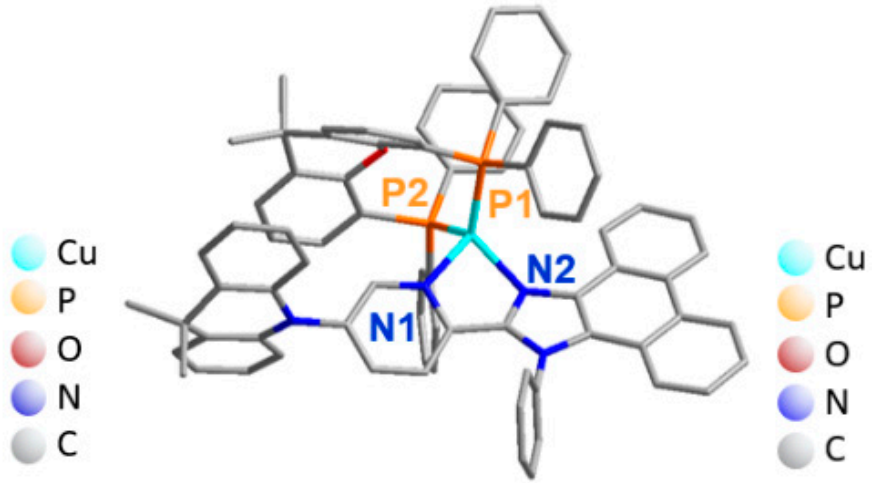

2

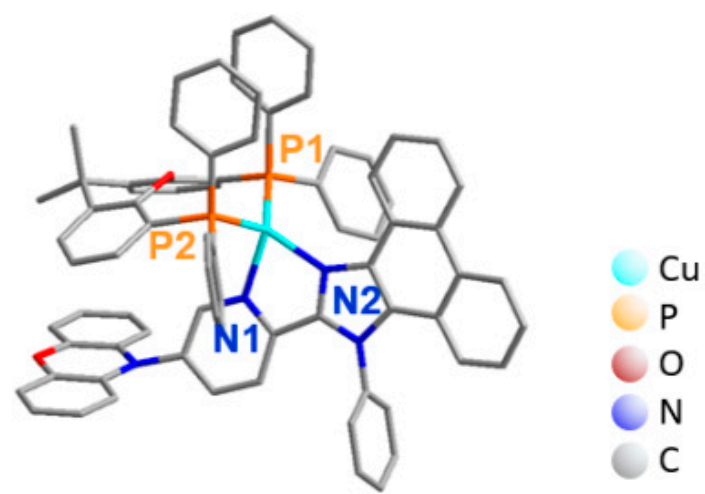

4

Figure 2. Crystal structures of complexes 1-4.

\subsection{Photophysical Properties}

Figure 3 a shows the absorption spectra of the $\mathrm{Cu}(\mathrm{I})$ complexes in $\mathrm{CH}_{2} \mathrm{Cl}_{2}$ at room temperature. The intense absorptions at $\lambda<300 \mathrm{~nm}$ are composed of $\pi \rightarrow \pi^{*}$ transitions of the phenyl-1H-phenanthro[9,10-d]imidazole (PI), the donor and the phosphine segments. The absorptions with maxima at 380-388 nm with molar absorptivity of ca. $3 \times 10^{4} \mathrm{M}^{-1}$ $\mathrm{cm}^{-1}$ are tentatively assigned to intraligand $\pi \rightarrow \pi^{*}$ transition of the planar PyPI moiety, probably with an admixture of charge transfer transition from the $\mathrm{Cu} / \mathrm{P}^{\wedge} \mathrm{P}$ to the $\mathrm{N}^{\wedge} \mathrm{N}$ ligand. The weaker and broad absorption tailing to $500 \mathrm{~nm}$ for $\mathbf{1} / \mathbf{2}$ and to $530 \mathrm{~nm}$ for $\mathbf{3 / 4}$ are assigned as intraligand charge-transfer (ILCT) transitions from the donor (DMAC and PXZ) to the PyPI; the redshifted absorptions for $3 / 4$ in comparison to $1 / 2$ are consistent with the stronger electron-donating capability of PXZ. The assignment of the lowest excited singlet state is supported by the density functional theory (DFT) calculations. As depicted in Figure $3 b$ and Figure S2 (Supplementary Materials), the HOMOs in all complexes predominantly localize on the donor (PXZ or DMAC) and the LUMOs are distributed over the PyPI moiety. Previously, similar ILCT character of the lowest excited states have been shown for Ag(I) complexes based on ligands DMAC-PyPI and PXZ-PyPI [31].

Emission properties of 1-4 were firstly examined in $\mathrm{CH}_{2} \mathrm{Cl}_{2}$ at room temperature. As depicted in Figure 3a, these complexes exhibit broad, structureless emissions with emission maxima of 514-537 $\mathrm{nm}$ upon photo-excitation $\left(\lambda_{\mathrm{ex}}=365 \mathrm{~nm}\right)$. The almost same emission energy and similar spectral profile for $1 / 2$ and for $3 / 4$ are in line with the $\mathrm{N}^{\wedge} \mathrm{N}$ liganddominated excited state. The significant overlap between the lowest energy absorption and the emission spectra reveals the emission origin from the first singlet excited state $\left(\mathrm{S}_{1}\right)$. The PLQYs of 1-4 in deaerated $\mathrm{CH}_{2} \mathrm{Cl}_{2}$ are $0.042-0.095$. The excited state structural flattening and thus exciplex formation are typically encountered for $\mathrm{Cu}(\mathrm{I})$ complexes with metalto-ligand charge-transfer (MLCT) excited state, which result in low photoluminescence 
quantum yields $[33,34]$. In view of the sterically congested features of the $\mathrm{P}^{\wedge} \mathrm{P}$ and $\mathrm{N}^{\wedge} \mathrm{N}$ ligands and the ligand-dominated excited state, such structural change is unlikely to occur in the present cases. Instead, torsional dynamics of the donor moieties and the phenyl ring on the $\mathrm{N}^{\wedge} \mathrm{N}$ ligand in fluid solution are conceived to induce fast non-radiative decay, thus giving low emission efficiencies of $\mathbf{1}-\mathbf{4}$.

a)

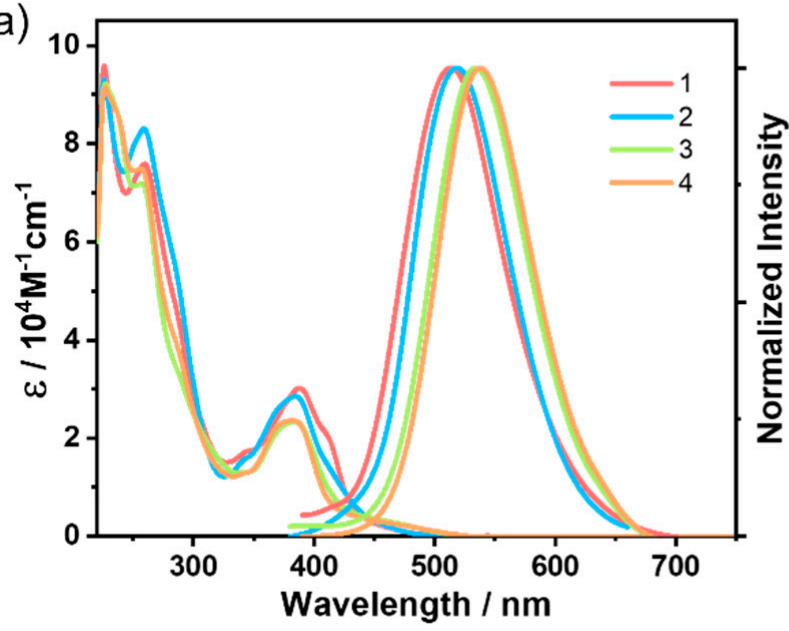

b)
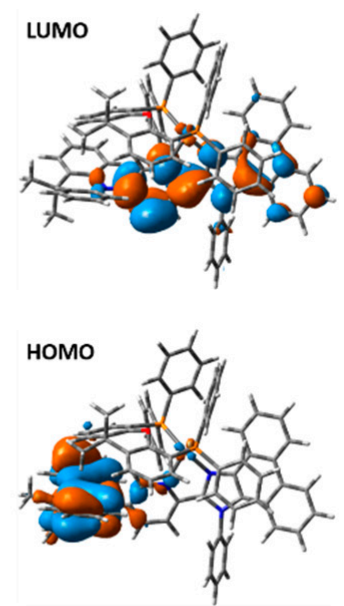

2
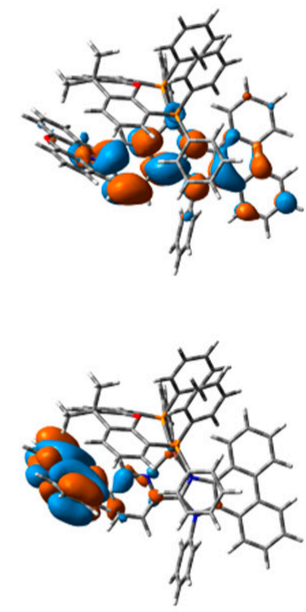

4

Figure 3. (a) UV-vis absorption and emission spectra of 1-4 in $\mathrm{CH}_{2} \mathrm{Cl}_{2}$ solution $\left(1 \times 10^{-5} \mathrm{M}\right)$ at $298 \mathrm{~K}$; (b) Frontier molecular orbitals for 2 and 4 at their optimized ground state geometries.

Then, the emission properties of 1-4 in bis[2-(diphenylphosphino)phenyl]ether oxide (DPEPO), 1,3-bis(N-carbazolyl) benzene (mCP), and poly-(methyl methacrylate) (PMMA) films were studied. All the numerical data are compiled in Table 1 and Table S3 (Supplementary Materials). As depicted in Figure $4 \mathrm{a}$, the photoluminescence (PL) spectra ( $\lambda_{\max }$ $=533-565 \mathrm{~nm})$ of all the complexes in DPEPO films $(10 \mathrm{wt} \%)$ at room temperature show characteristic $\mathrm{CT}$ emissions that are redshifted from their emissions in $\mathrm{CH}_{2} \mathrm{Cl}_{2}$ by 15-31 $\mathrm{nm}$; the larger bathochromic shift for $\mathbf{3}$ and $\mathbf{4}$ than for $\mathbf{1}$ and $\mathbf{2}$ are likely due to the stronger charge-transfer excited state nature of the former two complexes. This can be interpreted by the stronger electron-donating capability of PXZ compared with DMAC. Remarkably, the PLQYs for all complexes are increased to $0.42-0.71$ in the DPEPO films (Table 1) which can be ascribed to the suppressed intramolecular motions in the rigid solid matrix. Transient photoluminescence decay studies of the doped DPEPO films registered at their emission maxima show dominant decay times of 4.3-24.1 $\mu$ s under argon atmosphere (Figure $4 \mathrm{~b}$ ). As shown in Figure 4c,d, similar excited state dynamics were also supported by the timeresolved emission mapping measurements of 2 and 4 . The emission lifetime scale precludes the phosphorescence nature for their emissions because triplet excited states featuring very minor $\mathrm{d}$ orbital participation of $\mathrm{Cu}(\mathrm{I})$ are presumed to have much longer emission lifetimes. This speculation can be manifested by the much longer emission lifetime of 4 at lower temperature (vide infra). The strong temperature independence of emission lifetimes reveals the large variation of radiative decay rate with temperature changes, which is determined by the emitting state nature. Thus, the emissions for 1-4 at room temperature are assigned to $\mathrm{TADF}$, as that for $\mathrm{Ag}(\mathrm{I})$ analogues with the same ligands [31]. Notably, prompt fluorescence was not observed in the transient photoluminescent studies of each complex. The absence of prompt fluorescence in TADF metal complexes have been frequently found for $\mathrm{Cu}(\mathrm{I}), \mathrm{Au}(\mathrm{I}), \mathrm{Au}(\mathrm{III})$ complexes, which can be ascribed to the trivial but non-negligible heavy atom effect of the metal center in boosting the ISC process. To confirm the emission mechanism, phosphorescence spectra of the four emitters were probed at $77 \mathrm{~K}$. As depicted in Figure 4a, complexes $\mathbf{1}$ and $\mathbf{2}$ exhibit vibronically structured emission with peak/shoulder at $544 \mathrm{~nm} / 581 \mathrm{~nm}$ and $545 \mathrm{~nm} / 579 \mathrm{~nm}$, respectively. Differently, complexes 3 and 4 exhibit broad profiles with emission peaks at $582 \mathrm{~nm}$ and $575 \mathrm{~nm}$, respectively. The 
change in the emission band profile and the cryogenic shift are typical for TADF molecules, which lead to the conclusion that the triplet excited states at $77 \mathrm{~K}$ have significant ${ }^{3} \mathrm{LE}$ and ${ }^{3}$ ILCT characters for $\mathbf{1} / \mathbf{2}$ and $\mathbf{3} / \mathbf{4}$, respectively. The $\Delta E_{\mathrm{ST}}$ values for all the complexes are estimated to be $0.05-0.11 \mathrm{eV}$ based on the emission onsets of their fluorescence and phosphorescence spectra (Table 1), favorable for the TADF emissions at room temperature. For comparison, the emission properties of 1-4 in the films of PMMA and mCP were also studied. As depicted in Figures S3 and S4 and Table S3 (Supplementary Materials), similar emission spectral characteristics to those in DPEPO at both room temperature and $77 \mathrm{~K}$ were observed for all the complexes.

Table 1. The photophysical properties of complexes 1-4.

\begin{tabular}{|c|c|c|c|c|c|c|c|}
\hline \multirow[t]{2}{*}{ Complex } & \multicolumn{2}{|c|}{ In DCM } & \multicolumn{5}{|c|}{ In DPEPO } \\
\hline & $\lambda_{\mathrm{em}}[\mathrm{nm}]^{1}$ & PLQY ${ }^{1,2}$ & $\lambda_{\mathrm{em}}[\mathrm{nm}]^{3}$ & $\lambda_{\mathrm{em}}[\mathrm{nm}]^{4}$ & $\mathrm{~S}_{1} / \mathrm{T}_{1} / \Delta E_{\mathrm{ST}}{ }^{5}[\mathrm{eV}]$ & $\tau /[\mu \mathrm{s}]^{6}$ & PLQY 2,3 \\
\hline 1 & 514 & 0.06 & 534 & 544 & $2.56 / 2.45 / 0.11$ & 21.4 & 0.62 \\
\hline 2 & 518 & 0.095 & 533 & 545 & $2.55 / 2.47 / 0.08$ & 24.1 & 0.71 \\
\hline 3 & 534 & 0.05 & 565 & 582 & $2.46 / 2.39 / 0.07$ & 5.8 & 0.48 \\
\hline 4 & 537 & 0.042 & 564 & 575 & $2.48 / 2.43 / 0.05$ & 4.3 & 0.42 \\
\hline
\end{tabular}

${ }^{1}$ Measured in degassed dichloromethane (DCM) solution $\left(1 \times 10^{-5} \mathrm{M}\right)$ at $298 \mathrm{~K} .{ }^{2}$ Absolute photoluminescence quantum yields (PLQY) with an error of $( \pm 10 \%) .{ }^{3}$ Measured in $10 \mathrm{wt} . \%$ doped DPEPO film $298 \mathrm{~K} .{ }^{4}$ Measured in DPEPO film at $77 \mathrm{~K} .{ }^{5}$ Estimated from the emission onsets of the fluorescence $(298 \mathrm{~K})$ and phosphorescence $(77 \mathrm{~K})$ spectra in the DPEPO film. ${ }^{6}$ Emission decay times of emitters doped into DPEPO.

a)
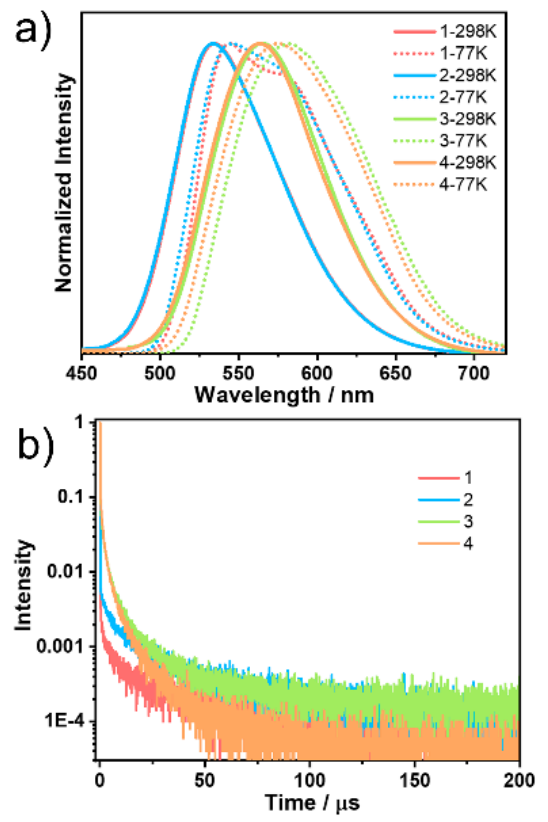

c)

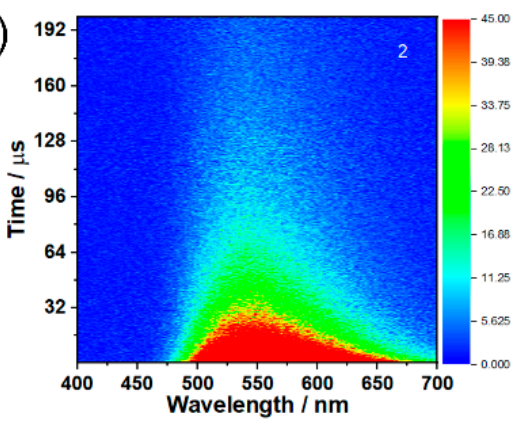

d)

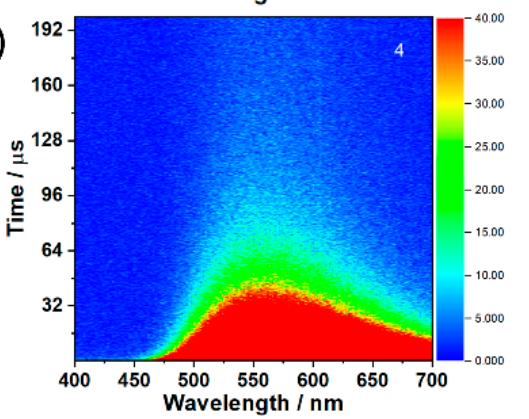

e)

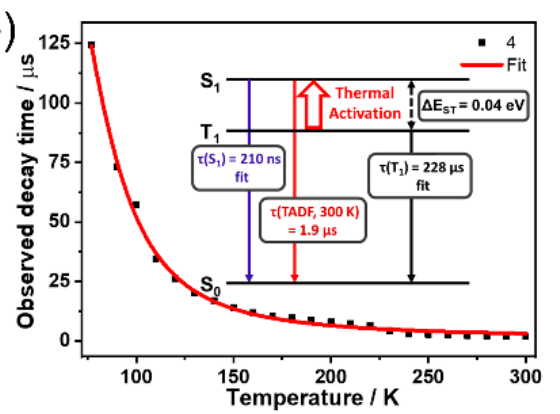

f)

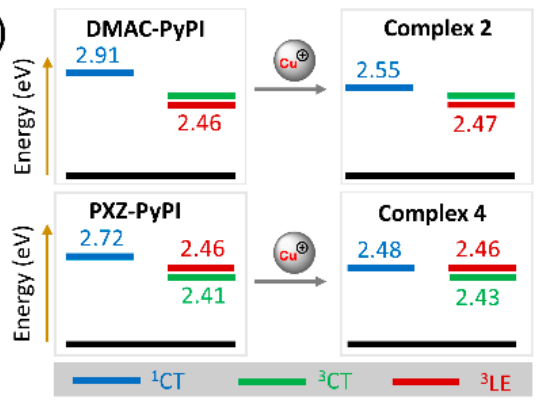

Figure 4. Photophysical properties of the $\mathrm{Cu}(\mathrm{I})$ complexes in DPEPO films: (a) photoluminescence (PL) spectra at $298 \mathrm{~K}$ and $77 \mathrm{~K}$; (b) transient PL characteristics for 1-4; time-resolve PL spectra of (c) 2 and (d) 4; (e) analysis of the variable temperature emission lifetimes of $\mathbf{4}$ using a Boltzmann-type equation; (f) proposed excited state energy levels for $\mathbf{2}$ and $\mathbf{4}$.

Variable temperature emission lifetimes of 4 in its powder state were measured at $77-300 \mathrm{~K}$ to further confirm the emission mechanism. According to the literature report [35], the observed decay time $\left(\tau_{\text {obs }}\right)$ can be described by the following equation in the tested temperature range:

$$
\tau=\frac{1+\frac{1}{3} \exp \left(-\frac{\Delta E_{S T}}{k_{B} T}\right)}{\frac{1}{\tau\left(T_{1}\right)}+\frac{1}{3 \tau\left(S_{1}\right)} \exp \left(-\frac{\Delta E_{S T}}{k_{B} T}\right)}
$$


where $k_{B}$ is the Boltzmann constant, $\tau\left(S_{1}\right)$ and $\tau\left(T_{1}\right)$ are the decay lifetimes of the $S_{1}$ and $T_{1}$ states, and $\Delta E_{\mathrm{ST}}$ represents the energy difference between the $\mathrm{S}_{1}$ state and $\mathrm{T}_{1}$ state.

The experimental data were found to agree well with Boltzmann-type equation (Figure $4 \mathrm{e})$. At low temperature $(77 \mathrm{~K})$, the observed lifetime of $124 \mu$ indicates that the cuprous complexes emit exclusive phosphorescence. As the temperature increases from $77 \mathrm{~K}$ to $130 \mathrm{~K}$, the emission lifetime shortens quickly as a result of thermal population of $\mathrm{S}_{1}$, which equilibrates with the $\mathrm{T}_{1}$ state according to Boltzmann statics. Further increasing the temperature to $240 \mathrm{~K}$ leads to a steady decrease of the lifetime. In this temperature range, the emission is composed of radiations from both $S_{1}$ and $T_{1}$ states; that is, TADF and phosphorescence. At the temperatures above $240 \mathrm{~K}$, the lifetimes keep almost unchanged, suggesting that the population of $S_{1}$ is highly favored and TADF dominates the emission. The $\Delta E_{\mathrm{ST}}$ is fitted to be $0.04 \mathrm{eV}$, which is in good agreement with the estimated value $(0.05 \mathrm{eV})$ based on the emission spectra. The similar $\Delta E_{\mathrm{ST}}$ values estimated using both methods reveal the similar molecular geometries at both room temperature and $77 \mathrm{~K}$ [36].

A notable finding in the photophysical properties of this series of $\mathrm{Cu}(\mathrm{I})$ complexes is the large difference of the delayed fluorescence lifetimes between $1 / 2$ and 3/4. The 4-6 fold shorter lifetimes of $3 / 4$ obviously reflect their faster RISC rate. A schematic diagram showing the effect of copper ion coordination on the excited states energy levels of DMACPyPI and PXZ-PyPI and on the excited state electronic structures is shown in Figure 4f. The $\mathrm{S}_{1}$ and $\mathrm{T}_{1}$ energies of DMAC-PyPI and PXZ-PyPI have been studied elsewhere and the large $\Delta E_{\mathrm{ST}}$ values of $0.31-0.45 \mathrm{eV}$ rationalize their prompt fluorescence [32]. It is noted that the $\mathrm{T}_{1}$ energies of both ligands are close to each other with a small difference of only $0.05 \mathrm{eV}$ despite the relatively larger difference of ca. $0.2 \mathrm{eV}$ for their $\mathrm{S}_{1}$ states. Further, the phosphorescence spectra of DMAC-PyPI is characterized by a vibronic progression while that of PXZ-PyPI is relatively broad and structureless. Therefore, a significant admixture of ${ }^{3} \mathrm{LE}$ character of the lowest triplet excited states is proposed for both ligands but energetic orderings of the ${ }^{3} \mathrm{LE}$ and ${ }^{3} \mathrm{CT}$ are reversed (Figure $4 \mathrm{f}$ ). Strikingly, coordination to $\mathrm{Cu}(\mathrm{I})$ ion does not change the triplet excited state energy level and the emission spectral profile. As shown in Figure $4 \mathrm{a}$, the $\mathrm{T}_{1}$ states of $\mathbf{1}$ and 2 have larger ${ }^{3} \mathrm{LE}$ parentage while that of 3 and 4 are dominated by the ${ }^{3} \mathrm{CT}$ state. Instead, the ${ }^{1} \mathrm{CT}$ states are stabilized by $0.26-0.36 \mathrm{eV}$ upon metal coordination, leading to a decrease of $\Delta E_{\mathrm{ST}}$ that becomes thermally accessible for TADF. In particular, the ${ }^{1} \mathrm{CT}$ and ${ }^{3} \mathrm{LE}$ for 3 and 4 are estimated to be energetic degenerate which is highly beneficial for RISC.

\subsection{Electroluminescence}

To examine the potential of this series of complexes for electroluminescence (EL), complexes $\mathbf{2}$ and $\mathbf{3}$ were selected for device fabrication. Complex $\mathbf{2}$ was studied because of the highest PLQY among the four complexes. Since the emission lifetime is also a crucial factor in determining the device performances, complex 3 was studied for comparison in view of its moderate PLQY but a beneficial short emission lifetime. The device structure of ITO/PEDOT:PSS (50 nm)/OTPD (4 nm)/PYD2: emitter (60 nm)/DPEPO (10 nm)/TPBi $(40 \mathrm{~nm}) / \mathrm{LiF}(1.2 \mathrm{~nm}) / \mathrm{Al}(100 \mathrm{~nm})$ was designed according to that for similar Ag(I) complexes [31]. The energy level diagrams and chemical structures of the organic materials are shown in Figure 5a,b. The HOMO levels of the $\mathrm{Cu}(\mathrm{I})$ complexes were determined by electrochemical studies and the LUMO levels can be deduced in combination with the optical bandgaps (Figure S5 and Table S4). For example, the HOMO/LUMO levels are estimated to be $-5.36 /-2.78 \mathrm{eV}$ for 2. Di(9H-carbazol-9-yl)pyridine (PYD2) with a good hole-transporting ability and high triplet energy level $(3.03 \mathrm{eV})$ was used as host material in the emissive layer (EML). DPEPO and 1,3,5-tris(1-phenyl-1H-benzo[d]imidazol2-yl)benzene (TPBi) function as hole/exciton blocking and electron transporting materials, respectively. The cross-linkable $N, N^{\prime}$-bis(4-(6-((3-ethyloxetan-3-yl)methoxy))-hexylphenyl)$N, N^{\prime}$-diphenyl-4, $4^{\prime}$-diamine (OTPD) was used to facilitate the hole injection into the emissive layer (EML) and prevents exciton quenching from the PEDOT:PSS layer. The EML was deposited by spin-coating a chlorobenzene solution of PYD2 mixed with 2 or 3 at various 
doping concentrations. The device characteristics are provided in Figures S6 and S7 and Tables S5 and S6 (Supplementary Materials). A comparison of the best device performances for $\mathbf{2}$ and $\mathbf{3}$ is also shown in Figure 5c,d. At all doping concentrations, the devices doped with 2 exhibit orange EL (Figure S6). The emission with a peak wavelength around $560 \mathrm{~nm}$ corresponds to the Commission international de l'éclairage (CIE) coordinates $(0.43,0.54)$. The turn-on voltage $\left(\mathrm{V}_{\text {on }}\right)$ (brightness of $1 \mathrm{~cd} / \mathrm{m}^{2}$ ) was found to almost insensitive to the dopant concentration, being $6.2,6.3,6.4$ and $6.2 \mathrm{~V}$ for the devices with $8,16,24$ and $40 \mathrm{wt} \%$ doping levels of 2 . This feature is different from the devices doped with the $\operatorname{Ag}(\mathrm{I})$ counterparts bearing the same ligands. The highest device efficiencies were recorded at the doping level of $24 \mathrm{wt} \%$ for which a peak current efficiency of $18.23 \mathrm{~cd} / \mathrm{A}$, a maximum power efficiency of $9.98 \mathrm{~lm} / \mathrm{W}$, and a maximum EQE of 5.91\% were achieved. In agreement with their PL differences, complex 3 exhibits red-shifted electroluminescence compared with 2 and the CIE is close to $(0.51,0.49)$ (Figure S7 and Figure 5c). Notably, the maximum $\mathrm{EQE}$ of the device containing 3 is $7.96 \%$, higher than that for $\mathbf{2}$. In view of their PLQYs $(0.71$ for 2 vs. 0.48 for 3), a much higher exciton utilization efficiency is estimated for $\mathbf{3}$ than for $\mathbf{2}$, presumably due to the significantly shorter emission lifetime for 3 .
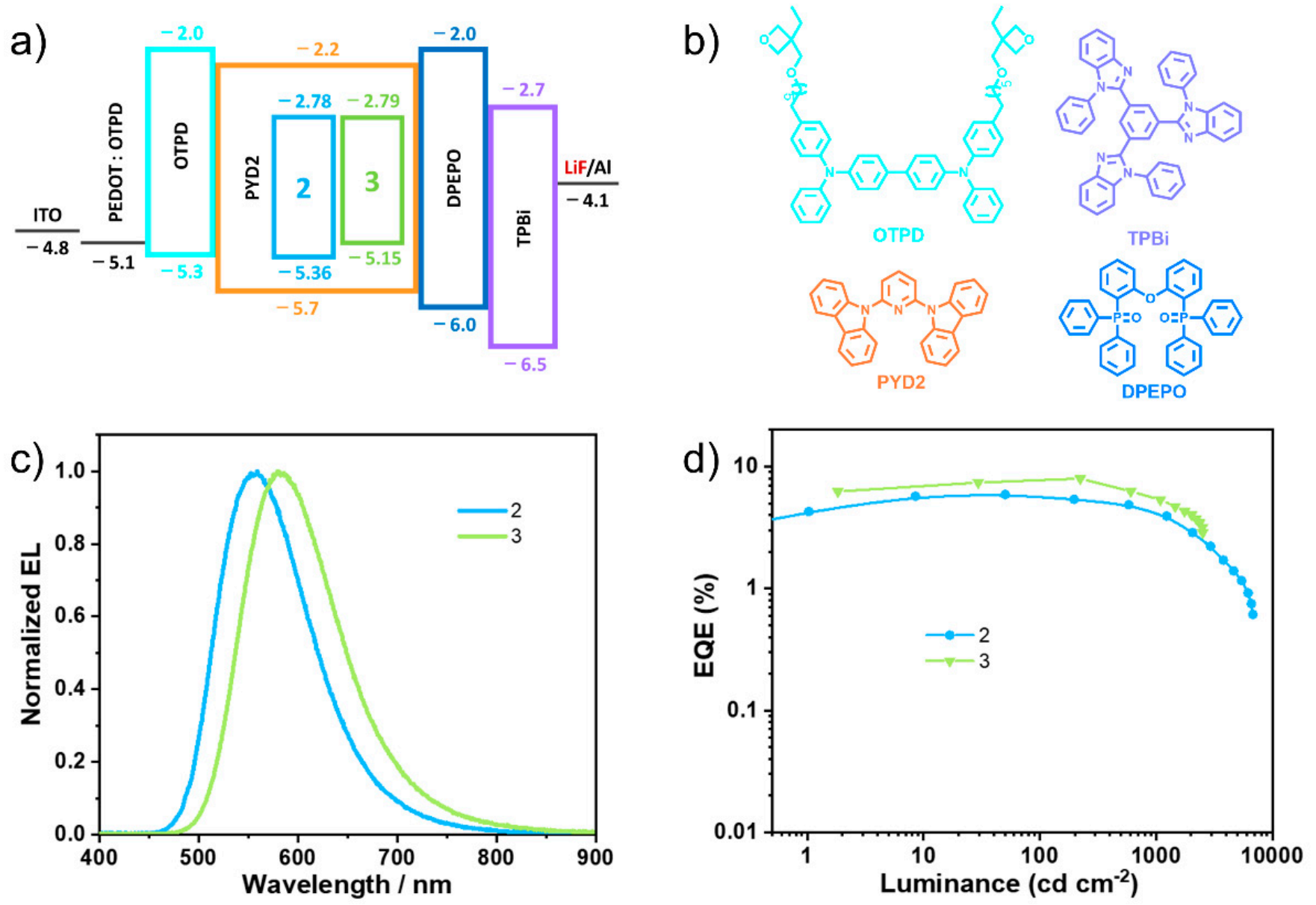

Figure 5. (a) The device configuration and (b) chemical structures of the organic materials used in the devices; (c) electroluminescence (EL) spectra of the optimized devices; (d) plots of external quantum efficiency versus luminance.

\section{Materials and Methods}

\subsection{General Information}

All Chemicals were purchased from commercial sources and used as received. The solvents for reactions were purified by solvent purification system before use. ${ }^{1} \mathrm{H}$ and ${ }^{31} \mathrm{P}\left\{{ }^{1} \mathrm{H}\right\}$ nuclear magnetic resonance (NMR) spectra were recorded on an AVANCE $400 \mathrm{MHz}$ 
superconducting-magnet high-field NMR spectrometer (Bruker, Zürich, Switzerland). Elemental analyses $(\mathrm{C}, \mathrm{H}, \mathrm{N})$ were carried using a Vario EL III elemental analyzer (Elementar, Berlin, Germany). Thermogravimetric analysis (TGA) was performed on a Discovery TGA 55 instrument (TA Instruments, New Castle, DE, USA). UV-Vis absorption spectra were recorded on a UV-2600 spectrophotometer (Shimadzu, Japan). Photoluminescence (PL) spectra were recorded on a F-7100 fluorescence spectrophotometer (Hitachi, Tokyo, Japan). The transient PL decay characteristics were measured by a FluoTime 300 spectrometer (PicoQuant, Berlin, Germany). The variable-temperature transient PL measurements were performed with the aid of a continuous flow cryostat (Oxford Instruments, Ambingdon, UK). Absolute PLQYs were obtained using a Quantaurus-QY measurement system C13534 (Hamamatsu Photonics, Hamamatsu, Japan). Thin films for spectroscopic measurements were prepared by spin-coating a dichloromethane (DCM) solution of the host and the complex followed by thermal annealing at $60^{\circ} \mathrm{C}$ for $0.5 \mathrm{~h}$. Cyclic voltammetry was measured in nitrogen-purged DCM by a CHI600 electrochemical analyzer (Chenhua, China) with a glassy carbon working electrode, a platinum wire counter electrode, and an $\mathrm{Ag} / \mathrm{AgCl}$ reference electrode. Tetrabutylammonium hexafluorophosphate $\left(\mathrm{TBAPF}_{6}\right)(0.1 \mathrm{M})$ was used as the supporting electrolyte and ferrocenium/ferrocene $\left(\mathrm{Fc}^{+} / \mathrm{Fc}\right)$ was used as the internal standard.

\subsection{General Procedure for the Synthesis of $\mathrm{Cu}(\mathrm{I})$ Complexes}

A mixture of $\left(\mathrm{Cu}\left(\mathrm{CH}_{3} \mathrm{CN}\right)_{4}\right) \mathrm{BF}_{4}(1.0 \mathrm{mmol})$ and diimine ligand $(1.0 \mathrm{mmol})$ in acetonitrile $/ \mathrm{CH}_{2} \mathrm{Cl}_{2}(10 \mathrm{~mL} / 10 \mathrm{~mL})$ was stirred at room temperature for $1 \mathrm{~h}$ and then added corresponding POP or Xantphos $(1.0 \mathrm{mmol})$ in $\mathrm{CH}_{2} \mathrm{Cl}_{2}(10 \mathrm{~mL})$. The reaction mixture was stirred for another $1 \mathrm{~h}$, and the solvent was then evaporated. Single crystals of these complexes suitable for $\mathrm{X}$-ray diffraction measurements were obtained through slow evaporation of their solutions in mixed hexane/dichloromethane $(v / v, 3: 1)$.

(Cu(DMAC-PyPI)(POP))BF 4 (1). Yield: 81\%. ${ }^{1} \mathrm{H}$ NMR $\left(400 \mathrm{MHz}, \mathrm{CDCl}_{3}, 298 \mathrm{~K}\right) \delta$ $9.15(\mathrm{~d}, J=7.9 \mathrm{~Hz}, 1 \mathrm{H}), 8.71(\mathrm{~d}, J=8.4 \mathrm{~Hz}, 1 \mathrm{H}), 8.59(\mathrm{~d}, J=8.4 \mathrm{~Hz}, 1 \mathrm{H}), 8.44(\mathrm{~s}, 1 \mathrm{H}), 7.92$ $(\mathrm{d}, J=7.0 \mathrm{~Hz}, 3 \mathrm{H}), 7.60(\mathrm{~d}, J=7.9 \mathrm{~Hz}, 4 \mathrm{H}), 7.45(\mathrm{~d}, J=7.6 \mathrm{~Hz}, 3 \mathrm{H}), 7.30(\mathrm{t}, J=7.8 \mathrm{~Hz}, 1 \mathrm{H})$, $7.22(\mathrm{t}, J=7.4 \mathrm{~Hz}, 2 \mathrm{H}), 7.16-7.08(\mathrm{~m}, 10 \mathrm{H}), 7.05-6.96(\mathrm{~m}, 20 \mathrm{H}), 6.77(\mathrm{~d}, J=8.1 \mathrm{~Hz}, 2 \mathrm{H}), 6.65$ $(\mathrm{d}, J=8.9 \mathrm{~Hz}, 1 \mathrm{H}), 6.29(\mathrm{~d}, J=8.0 \mathrm{~Hz}, 2 \mathrm{H}), 1.46(\mathrm{~s}, 6 \mathrm{H}) .{ }^{31} \mathrm{P} \mathrm{NMR}\left(162 \mathrm{MHz}, \mathrm{CDCl}_{3}, 298\right.$ K) $\delta-11.74$ (s). Anal. calcd for $\mathrm{C}_{77} \mathrm{H}_{58} \mathrm{BCuF}_{4} \mathrm{~N}_{4} \mathrm{OP}_{2} .0 .5 \mathrm{CH}_{2} \mathrm{Cl}_{2}$ : C, 71.05; $\mathrm{H}, 4.54 ; \mathrm{N}, 4.28$. Found: C, 70.92; H, 4.84; N, 4.15 .

(Cu(DMAC-PyPI)(Xantphos))BF 4 (2). Yield: 79\%. ${ }^{1} \mathrm{H}$ NMR $\left(400 \mathrm{MHz}, \mathrm{CDCl}_{3}, 298 \mathrm{~K}\right)$ $\delta 8.85(\mathrm{~d}, J=7.7 \mathrm{~Hz}, 1 \mathrm{H}), 8.71(\mathrm{~d}, J=8.4 \mathrm{~Hz}, 1 \mathrm{H}), 8.60(\mathrm{~d}, J=8.5 \mathrm{~Hz}, 1 \mathrm{H}), 7.95(\mathrm{~d}, J=7.2 \mathrm{~Hz}$, $3 \mathrm{H}), 7.84(\mathrm{~s}, 1 \mathrm{H}), 7.62(\mathrm{~m}, 4 \mathrm{H}), 7.46(\mathrm{~d}, J=7.8 \mathrm{~Hz}, 5 \mathrm{H}), 7.33(\mathrm{~m}, 3 \mathrm{H}), 7.18(\mathrm{t}, J=7.2 \mathrm{~Hz}, 2 \mathrm{H})$, $7.10(\mathrm{~m}, 5 \mathrm{H}), 7.06-6.87(\mathrm{~m}, 18 \mathrm{H}), 6.77-6.71(\mathrm{~m}, 2 \mathrm{H}), 6.60-6.55(\mathrm{~m}, 2 \mathrm{H}), 5.81(\mathrm{~d}, J=8.1 \mathrm{~Hz}$, $2 \mathrm{H}), 1.63(\mathrm{~s}, 6 \mathrm{H}), 1.61(\mathrm{~s}, 6 \mathrm{H}) .{ }^{31} \mathrm{P} \mathrm{NMR}\left(162 \mathrm{MHz}, \mathrm{CDCl}_{3}, 298 \mathrm{~K}\right) \delta-12.77$ (s). Anal. calcd for $\mathrm{C}_{80} \mathrm{H}_{62} \mathrm{BCuF}_{4} \mathrm{~N}_{4} \mathrm{OP}_{2} .0 .5 \mathrm{CH}_{2} \mathrm{Cl}_{2}$.EtOH: C, 70.97; H, 4.98; N, 4.01. Found: C, 71.01; H, $4.87 ; \mathrm{N}, 4.01$.

(Cu(PXZ-PyPI)(POP))BF 4 (3). Yield: 84\%. ${ }^{1} \mathrm{H}$ NMR (400 MHz, CDCl $\left.3,298 \mathrm{~K}\right) \delta 9.13$ $(\mathrm{d}, J=7.9 \mathrm{~Hz}, 1 \mathrm{H}), 8.71(\mathrm{~d}, J=8.4 \mathrm{~Hz}, 1 \mathrm{H}), 8.58(\mathrm{~d}, J=8.4 \mathrm{~Hz}, 1 \mathrm{H}), 8.33(\mathrm{~d}, J=2.0 \mathrm{~Hz}, 1 \mathrm{H})$, 7.97-7.90 (m, 3H), $7.61(\mathrm{~m}, 4 \mathrm{H}), 7.47(\mathrm{t}, J=7.7 \mathrm{~Hz}, 1 \mathrm{H}), 7.33-7.29(\mathrm{~m}, 1 \mathrm{H}), 7.25-7.19(\mathrm{~m}$, $4 \mathrm{H}), 7.18-6.94(\mathrm{~m}, 26 \mathrm{H}), 6.79(\mathrm{~m}, 5 \mathrm{H}), 6.54(\mathrm{dt}, J=8.6,4.5 \mathrm{~Hz}, 2 \mathrm{H}), 5.65(\mathrm{~d}, J=8.0 \mathrm{~Hz}, 2 \mathrm{H})$. ${ }^{31} \mathrm{P}$ NMR $\left(162 \mathrm{MHz}, \mathrm{CDCl}_{3}, 298 \mathrm{~K}\right) \delta-12.30$ (s). Anal. calcd for $\mathrm{C}_{74} \mathrm{H}_{52} \mathrm{BCuF}_{4} \mathrm{~N}_{4} \mathrm{O}_{2} \mathrm{P}_{2}$. $0.5 \mathrm{CH}_{2} \mathrm{Cl}_{2}$ : C, 69.69; H, 4.16; N, 4.36. Found: C, 70.16; H, 4.32; N, 4.17.

(Cu(PXZ-PIPy)(Xantphos))BF (4). Yield: 77\%. ${ }^{1} \mathrm{H}$ NMR (400 $\left.\mathrm{MHz}_{4} \mathrm{CDCl}_{3}, 298 \mathrm{~K}\right)$ $9.22(\mathrm{~d}, J=7.4 \mathrm{~Hz}, 1 \mathrm{H}), 8.72(\mathrm{~d}, J=8.3 \mathrm{~Hz}, 1 \mathrm{H}), 8.64(\mathrm{~d}, J=8.4 \mathrm{~Hz}, 1 \mathrm{H}), 8.00-7.93(\mathrm{~m}, 3 \mathrm{H})$, $7.73(\mathrm{dd}, J=6.6,2.9 \mathrm{~Hz}, 2 \mathrm{H}), 7.64-7.52(\mathrm{~m}, 3 \mathrm{H}), 7.41-7.30(\mathrm{~m}, 4 \mathrm{H}), 7.25-7.09(\mathrm{~m}, 14 \mathrm{H}), 7.05$ $(\mathrm{t}, J=7.9 \mathrm{~Hz}, 5 \mathrm{H}), 6.93-6.80(\mathrm{~m}, 6 \mathrm{H}), 6.73-6.65(\mathrm{~m}, 4 \mathrm{H}), 6.47(\mathrm{dt}, J=7.6,3.9 \mathrm{~Hz}, 2 \mathrm{H}), 6.36(\mathrm{t}$, $J=7.6 \mathrm{~Hz}, 2 \mathrm{H}), 5.30(\mathrm{~d}, J=8.0 \mathrm{~Hz}, 2 \mathrm{H}), 1.60(\mathrm{~s}, 6 \mathrm{H}) .{ }^{31} \mathrm{P} \mathrm{NMR}\left(162 \mathrm{MHz}, \mathrm{CDCl}_{3}, 298 \mathrm{~K}\right) \delta$ -11.83 (s). Anal. calcd for $\mathrm{C}_{77} \mathrm{H}_{56} \mathrm{BCuF}_{4} \mathrm{~N}_{4} \mathrm{O}_{2} \mathrm{P}_{2}$ : C, 72.16; $\mathrm{H}, 4.40 ; \mathrm{N}, 4.37$. Found: $\mathrm{C}, 71.93$; $\mathrm{H}, 4.17 ; \mathrm{N}, 4.06$. 


\section{Conclusions}

A new series of $\mathrm{Cu}(\mathrm{I})$ complexes exhibiting green-orange TADF emissions have been developed by using simple D-A type $\mathrm{N}^{\wedge} \mathrm{N}$ ligands and ancillary phosphine ligands. The metal ion coordination induces a decrease of $\Delta E_{\mathrm{ST}}$ for the ligand-centered excited states, resulting in the emission switching from fluorescence for free $\mathrm{N}^{\wedge} \mathrm{N}$ ligands to TADF for the $\mathrm{Cu}(\mathrm{I})$ complexes. High PLQYs of up to 0.71 in doped films have been recorded for the $\mathrm{Cu}(\mathrm{I})$ complexes. The donor strength of the $\mathrm{N}^{\wedge} \mathrm{N}$ ligand has a large impact on the energy level of the intraligand charge-transfer excited state and thus on the energetic ordering of the ${ }^{3} \mathrm{CT}$ and ${ }^{3} \mathrm{LE}$ states. As a result, the emission lifetimes of the $\mathrm{Cu}(\mathrm{I})$ complexes vary by more than 4-folds. High efficiency OLEDs with maximum EQEs of up to $7.96 \%$ have been achieved and the shorter emission lifetime was found to be beneficial for a high EQE. The encouraging results combined with rational design strategies in this study may provide a guide for developing highly efficient cuprous complexes and OLEDs.

Supplementary Materials: The following are available online: computational methods; details for device fabrications and measurements; TGA curves of 1-4 (Figure S1); crystal data and selected structural parameters of 1-4 (Tables S1 and S2); calculated FMOs of 1 and 3 (Figure S2); emission spectra and decay characteristics of 1-4 in PMMA and mCP films (Figures S3 and S4 and Table S3); cyclic voltammograms of 1-4 (Figure S5 and Table S4); device performances of 2 and 3 (Figures S6 and S7 and Tables S5 and S6).

Author Contributions: K.L. conceived and designed the project. T.T., J.X., and X.L. performed the syntheses, structural characterizations, and spectroscopic measurements of the $\mathrm{Cu}(\mathrm{I})$ complexes. C.Z. performed the DFT calculations. G.C. fabricated and tested the OLEDs. K.L. and T.T. analyzed the data. K.L. wrote the paper. All authors have read and agreed to the published version of the manuscript.

Funding: This research was funded by National Natural Science Foundation of China (21801170), the Shenzhen Science and Technology Program (JCYJ20190808172203553 and JCYJ20200109150414471), and the Department of Science and Technology of Guangdong Province (2019QN01C617).

Institutional Review Board Statement: Not applicable.

Informed Consent Statement: Not applicable.

Data Availability Statement: The data presented in this study are available in article and Supplementary Materials here.

Conflicts of Interest: The authors declare no conflict of interest.

Sample Availability: Samples of the compounds are not available from the authors.

\section{References}

1. Li, K.; Tong, G.S.M.; Wan, Q.; Cheng, G.; Tong, W.-Y.; Ang, W.-H.; Kwong, W.-L.; Che, C.-M. Highly phosphorescent platinum(II) emitters: Photophysics, materials and biological applications. Chem. Sci. 2016, 7, 1653-1673. [CrossRef]

2. Yang, X.; Zhou, G.; Wong, W.-Y. Functionalization of phosphorescent emitters and their host materials by main-group elements for phosphorescent organic light-emitting devices. Chem. Soc. Rev. 2015, 44, 8484-8575. [CrossRef]

3. Fan, C.; Yang, C. Yellow/orange emissive heavy-metal complexes as phosphors in monochromatic and white organic lightemitting devices. Chem. Soc. Rev. 2014, 43, 6439-6469. [CrossRef]

4. Xu, H.; Chen, R.; Sun, Q.; Lai, W.; Su, Q.; Huang, W.; Liu, X. Recent progress in metal-organic complexes for optoelectronic applications. Chem. Soc. Rev. 2014, 43, 3259-3302. [CrossRef]

5. Chou, P.-T.; Chi, Y.; Chung, M.-W.; Lin, C.-C. Harvesting luminescence via harnessing the photophysical properties of transition metal complexes. Coord. Chem. Rev. 2011, 255, 2653-2665. [CrossRef]

6. Evans, R.C.; Douglas, P.; Winscom, C.J. Coordination complexes exhibiting room-temperature phosphorescence: Evaluation of their suitability as triplet emitters in organic light emitting diodes. Coord. Chem. Rev. 2006, 250, 2093-2126. [CrossRef]

7. Ho, P.-Y.; Ho, C.-L.; Wong, W.-Y. Recent advances of iridium(III) metallophosphors for health-related applications. Coord. Chem. Rev. 2020, 413, 213267. [CrossRef]

8. Zhang, X.; Hou, Y.; Xiao, X.; Chen, X.; Hu, M.; Geng, X.; Wang, Z.; Zhao, J. Recent development of the transition metal complexes showing strong absorption of visible light and long-lived triplet excited state: From molecular structure design to photophysical properties and applications. Coord. Chem. Rev. 2020, 417, 213371. [CrossRef] 
9. Arias-Rotondo, D.M.; McCusker, J.K. The photophysics of photoredox catalysis: A roadmap for catalyst design. Chem. Soc. Rev. 2016, 45, 5803-5820. [CrossRef] [PubMed]

10. Zhao, J.; Wu, W.; Sun, J.; Guo, S. Triplet photosensitizers: From molecular design to applications. Chem. Soc. Rev. 2013, 42, 5323-5351. [CrossRef]

11. Barbieri, A.; Accorsi, G.; Armaroli, N. Luminescent complexes beyond the platinum group: The d ${ }^{10}$ avenue. Chem. Commun. 2008, 2185-2193. [CrossRef] [PubMed]

12. Wenger, O.S. Photoactive Complexes with Earth-Abundant Metals. J. Am. Chem. Soc. 2018, 140, 13522-13533. [CrossRef]

13. To, W.-P.; Chan, K.T.; Tong, G.S.M.; Ma, C.; Kwok, W.-M.; Guan, X.; Low, K.-H.; Che, C.-M. Strongly luminescent gold(III) complexes with long-lived excited states: High emission quantum yields, energy up-conversion, and nonlinear optical properties. Angew. Chem. Int. Ed. 2013, 52, 6648-6652. [CrossRef] [PubMed]

14. To, W.-P.; Tong, G.S.M.; Lu, W.; Ma, C.; Liu, J.; Chow, A.L.-F.; Che, C.-M. Luminescent organogold(III) complexes with long-lived triplet excited states for light-induced oxidative $\mathrm{C}-\mathrm{H}$ bond functionalization and hydrogen production. Angew. Chem. Int. Ed. 2012, 51, 2654-2657. [CrossRef] [PubMed]

15. Uoyama, H.; Goushi, K.; Shizu, K.; Nomura, H.; Adachi, C. Highly efficient organic light-emitting diodes from delayed fluorescence. Nature 2012, 492, 234-238. [CrossRef]

16. Czerwieniec, R.; Yu, J.; Yersin, H. Blue-light emission of $\mathrm{Cu}(\mathrm{I})$ complexes and singlet harvesting. Inorg. Chem. 2011, 50, 8293-8301. [CrossRef]

17. Chen, X.-L.; Yu, R.; Zhang, Q.-K.; Zhou, L.-J.; Wu, X.-Y.; Zhang, Q.; Lu, C.-Z. Rational design of strongly blue-emitting cuprous complexes with thermally activated delayed fluorescence and application in solution-processed OLEDs. Chem. Mater. 2013, 25, 3910-3920. [CrossRef]

18. Chen, X.-L.; Lin, C.-S.; Wu, X.-Y.; Yu, R.; Teng, T.; Zhang, Q.-K.; Zhang, Q.; Yang, W.-B.; Lu, C.-Z. Highly efficient cuprous complexes with thermally activated delayed fluorescence and simplified solution process OLEDs using the ligand as host. J. Mater. Chem. C 2015, 3, 1187-1195. [CrossRef]

19. Liang, D.; Chen, X.-L.; Liao, J.-Z.; Hu, J.-Y.; Jia, J.-H.; Lu, C.-Z. Highly efficient cuprous complexes with thermally activated delayed fluorescence for solution-processed organic light-emitting devices. Inorg. Chem. 2016, 55, 7467-7475. [CrossRef]

20. Klein, M.; Rau, N.; Wende, M.; Sundermeyer, J.; Cheng, G.; Che, C.-M.; Schinabeck, A.; Yersin, H. Cu(I) and Ag(I) complexes with a new type of rigid tridentate n,p,p-ligand for thermally activated delayed fluorescence and OLEDs with high external quantum efficiency. Chem. Mater. 2020, 32, 10365-10382. [CrossRef]

21. So, G.K.-M.; Cheng, G.; Wang, J.; Chang, X.; Kwok, C.-C.; Zhang, H.; Che, C.-M. Efficient color-tunable copper(I) complexes and their applications in solution-processed organic light-emitting diodes. Chem. Asian J. 2017, 12, 1490-1498. [CrossRef]

22. Osawa, M.; Hoshino, M.; Hashimoto, M.; Kawata, I.; Igawa, S.; Yashima, M. Application of three-coordinate copper(I) complexes with halide ligands in organic light-emitting diodes that exhibit delayed fluorescence. Dalton Trans. 2015, 44, 8369-8378. [CrossRef]

23. Czerwieniec, R.; Leitl, M.J.; Homeier, H.H.H.; Yersin, H. Cu(I) complexes-Thermally activated delayed fluorescence. Photophysical approach and material design. Coord. Chem. Rev. 2016, 325, 2-28. [CrossRef]

24. To, W.-P.; Cheng, G.; Tong, G.S.M.; Zhou, D.; Che, C.-M. Recent advances in metal-TADF emitters and their application in organic light-emitting diodes. Front. Chem. 2020, 8, 653. [CrossRef] [PubMed]

25. Mahoro, G.U.; Fernandez-Cestau, J.; Renaud, J.-L.; Coto, P.B.; Costa, R.D.; Gaillard, S. Recent advances in solid-state lighting devices using transition metal complexes exhibiting thermally activated delayed fluorescent emission mechanism. Adv. Optical Mater. 2020, 8, 2000260. [CrossRef]

26. Shi, S.; Jung, M.C.; Coburn, C.; Tadle, A.; Sylvinson, M.R.D.; Djurovich, P.I.; Forrest, S.R.; Thompson, M.E. Highly efficient photoand electroluminescence from two-coordinate $\mathrm{Cu}(\mathrm{I})$ complexes featuring nonconventional N-heterocyclic carbenes. J. Am. Chem. Soc. 2019, 141, 3576-3588. [CrossRef]

27. Hamze, R.; Peltier, J.L.; Sylvinson, D.; Jung, M.; Cardenas, J.; Haiges, R.; Soleilhavoup, M.; Jazzar, R.; Djurovich, P.I.; Bertrand, G.; et al. Eliminating nonradiative decay in $\mathrm{Cu}(\mathrm{I})$ emitters: $>99 \%$ quantum efficiency and microsecond lifetime. Science 2019, 363, 601-606. [CrossRef]

28. Zhu, Z.-Q.; Fleetham, T.; Turner, E.; Li, J. Harvesting all electrogenerated excitons through metal assisted delayed fluorescent materials. Adv. Mater. 2015, 27, 2533-2537. [CrossRef] [PubMed]

29. Chan, K.-T.; Lam, T.-L.; Yu, D.; Du, L.; Phillips, D.L.; Kwong, C.-L.; Tong, G.S.-M.; Cheng, G.; Che, C.-M. Strongly luminescent tungsten emitters with emission quantum yields up to $84 \%$ : TADF and high-efficiency molecular tungsten OLEDs. Angew. Chem. Int. Ed. 2019, 58, 14896-14900. [CrossRef]

30. Zhou, D.; To, W.-P.; Tong, G.S.M.; Cheng, G.; Du, L.; Phillips, D.L.; Che, C.-M. Tetradentate gold(III) Complexes as thermally activated delayed fluorescence (TADF) emitters: Microwave-assisted synthesis and high-performance OLEDs with long operational lifetime. Angew. Chem. Int. Ed. 2020, 59, 6375-6382. [CrossRef]

31. Teng, T.; Li, K.; Cheng, G.; Wang, Y.; Wang, J.; Li, J.; Zhou, C.; Liu, H.; Zou, T.; Xiong, J.; et al. Lighting silver(I) complexes for solution-processed organic light-emitting diodes and biological applications via thermally activated delayed fluorescence. Inorg. Chem. 2020, 59, 12122-12131. [CrossRef] [PubMed]

32. Jia, J.-H.; Liang, D.; Yu, R.; Chen, X.-L.; Meng, L.; Chang, J.-F.; Liao, J.-Z.; Yang, M.; Li, X.-N.; Lu, C.-Z. Coordination-induced thermally activated delayed fluorescence: From non-TADF donor-acceptor-type ligand to TADF-active Ag-based complexes. Chem. Mater. 2020, 32, 620-629. [CrossRef] 
33. Zhang, Y.; Schulz, M.; Wächtler, M.; Karnahl, M.; Dietzek, B. Heteroleptic diimine-diphosphine Cu(I) complexes as an alternative towards noble-metal based photosensitizers: Design strategies, photophysical properties and perspective applications. Coord. Chem. Rev. 2018, 356, 127-146. [CrossRef]

34. Mara, M.W.; Fransted, K.A.; Chen, L.X. Interplays of excited state structures and dynamics in copper(I) diimine complexes: Implications and perspectives. Coord. Chem. Rev. 2015, 282-283, 2-18. [CrossRef]

35. Yersin, H.; Rausch, A.F.; Czerwieniec, R.; Hofbeck, T.; Fischer, T. The triplet state of organo-transition metal compounds. Triplet harvesting and singlet harvesting for efficient OLEDs. Coord. Chem. Rev. 2011, 255, 2622-2652. [CrossRef]

36. Ravinson, D.S.M.; Thompson, M.E. Thermally assisted delayed fluorescence (TADF): Fluorescence delayed is fluorescence denied. Mater. Horiz. 2020, 7, 1210-1217. [CrossRef] 